\title{
REIS, João José. Ganhadores: a greve negra de 1857 na Bahia. São Paulo: Cia das Letras, 2019,451p.
}

Valney Mascarenhas Lima Filho ${ }^{1}$

O autor João J. Reis em seu livro, Ganhadores: A greve negra de 1857 na Bahia, apresenta-nos um retrato social dos chamados "ganhadores", que ocuparam as ruas de Salvador ao longo do século XIX. A greve de ganhadores ocorreu em Salvador, no ano de 1857, e com ampla mobilização social da categoria colapsou o funcionamento da cidade. Em uma leitura fluída, agradável e densa as páginas conduzem para o dia a dia da lida desses trabalhadores africanos empregados ao ganho em Salvador na década de 1850. A maioria deles era composta por homens africanos nagôs, libertos ou escravizados, empregados ao ganho, responsáveis, principalmente, por carregar pessoas e mercadorias entre as ruas enladeiradas da capital baiana. Como indica o autor, "esse livro busca descrever e entender o que foi o primeiro movimento grevista envolvendo todo um setor sensível da classe trabalhadora urbana no Brasil, trabalhadores responsáveis pelo transporte, por toda cidade, de pessoas livres de vária ordem e objetos de todo tipo.” (p.17).

Nessa obra as principais fontes utilizadas foram correspondências, regulamentos, Instruções e posturas da Câmara Municipal de Salvador, correspondências do Chefe de Polícia, matrícula de escravos, periódicos, matrícula dos ganhadores, entre outras. O estilo de escrita fluído e sem muitos academicismos torna a leitura acessível tanto para o especialista quanto para o grande público desejoso de conhecer um pouco mais sobre a história da Bahia. O livro é composto de quinze capítulos, os quais abordam o período anterior e o contexto que se deu a greve de 1857, o processo da paralisação e seus

\footnotetext{
${ }^{1}$ Mestre em História pela Universidade Federal da Bahia. Atuação na Linha de Pesquisa Escravidão e Invenção da Liberdade.
} 
REIS, João José. Ganhadores: a greve negra de 1857 na Bahia. São Paulo: Cia das Letras, 2019,451p.

desdobramentos, e a continuidade do trabalho dos ganhadores na década de 1870 e 80 até às vésperas da abolição. Todos os capítulos dialogam entre si, no intuito de montar o cenário histórico do episódio.

No primeiro capítulo, Controle Noite e Dia, Reis aborda a postura municipal motivadora da greve, promulgada em 1857, que tinha o intuído de controlar os ganhadores escravizados, libertos ou livres. A legislação tornava obrigatória a matrícula junto à Câmara Municipal, para obter licença de trabalho, e o uso de uma chapa de metal contendo a identificação individual. A matrícula custaria 2mil-réis e a chapa 3mil-réis. "Tais medidas, entre muitas outras, foram concebidas pelos poderes públicos de Salvador para controlar, constranger, disciplinar e, no limite, expulsar da cidade os ganhadores africanos" (p.25). Como percebemos ao longo do livro, os africanos eram identificados como uma ameaça para ordem pública, assim, tornavam-se alvos preferenciais das autoridades. Na concepção dos brancos e senhores, lugar de africano era na lavoura ou então na Costa da África. Após o fim do contrabando de pessoas ilegalmente escravizadas, com a proclamação da Lei Euzébio de Queiroz, em 1850, a elite buscava atrair a migração branca europeia. Nesse cenário, os crioulos, negros nascidos no Brasil, ganhavam mais simpatia e confiança enquanto os africanos encarnavam a herança malquista da África. Com a diminuição da presença destes últimos no correr do século XIX, o controle e vigilância dos crioulos ganharam centralidade entre as autoridades de Salvador.

Apesar da hostilidade contra os africanos, eram os responsáveis por grande parte dos trabalhos de rua na cidade de Salvador. Ganhadores, em sua maioria homens provenientes de distintas partes da África, se ocuparam no transporte de mercadoria e pessoas entre as ruas e ladeiras, já as ganhadoras, principalmente mulheres africanas, se dedicaram à venda de farinha, frutas e quitutes nas ruas da cidade e assim impunham dinamismo e movimentavam a vida urbana. É sobre esse contexto que trata o segundo capítulo, Trabalho africano de rua. Dos anos finais do tráfico atlântico e contrabando até a década de 1850, a Bahia importou escravizados principalmente da Costa da Mina que 
pertenciam a grupos sociais de língua gbe (aja, fon, mahi, ewe etc.), iorubás e haussás, conhecidos na Bahia oitocentista, respectivamente, como jejes, nagôs e ussás. Como indica Reis, os nagôs eram a maioria e, na primeira metade do século XIX, construíram maior presença no seio da colônia africana local. A hegemonia nagô é um ponto crucial no entendimento das relações de trabalho entre os ganhadores. "Disciplinar o trabalhador africano, sobretudo na cidade, era tarefa ingrata, porque a liga étnica que orientava seu comportamento representava um formidável complicador para as autoridades policiais e civis" (p.39). Na formação de uma nação nagô não se apagava a memória de uma procedência específica na África, contudo, o grupo contou com língua e mitos de origem comuns para a construção de significados coletivos.

Outro ponto fundamental presente no livro é o entendimento do trabalho em conexão com a dimensão espiritual com raízes em África. Como indica Reis, "O universo simbólico africano, em grande parte renovado e atualizado na Bahia oitocentista, deve ser entendido em conexão com a experiência de trabalho dos escravos e libertos." (p.72). Esse aspecto é articulado com uma noção de economia moral do trabalho dos escravizados e libertos que estava em oposição à moral mercantil do senhor. $\mathrm{O}$ conceito vem de $\mathrm{E}$. $\mathrm{P}$. Thompson, que buscou articular o entendimento das reivindicações populares com os valores morais coletivos, ao invés de atribuir meramente motivos econômicos. No caso dos ganhadores, o ritmo do trabalho, os horários a serem cumpridos, e o modo de se apresentar nas ruas, constituíam costumes coletivos que os africanos buscaram preservar. Além da manifestação coletiva, como a da greve de 1857, os trabalhadores também resistiram individualmente desobedecendo sistematicamente as posturas municipais.

Nesse sentido, o terceiro capítulo, Canções, cantos e redes, disserta sobre o cotidiano dos ganhadores que entoavam músicas e ritmavam coletivamente os esforços de carregar pesados objetos e se juntavam nos cantos, onde ofereceriam seus serviços e teciam laços e redes de solidariedade. Os cantos, denominação dos locais de encontro dos ganhadores, foram muito importantes na constituição do trabalho, pois eram locais estratégicos em que se 
REIS, João José. Ganhadores: a greve negra de 1857 na Bahia. São Paulo: Cia das Letras, 2019,451p.

juntavam para oferecer seus serviços. Em outras cidades escravistas, como Rio de Janeiro e Recife, os trabalhadores também ocupavam as ruas oferecendo serviços, contudo, a denominação canto para esses coletivos laborais parece ter sido exclusiva da Bahia. Argumenta Reis: "A inspiração para esse tipo de organização pode ter origem em grupos de trabalho cooperativo comuns na África Ocidental, conhecidos ali como aro entre os nagôs e dókpwê entre os jejes.” (p.83). O primeiro registro da palavra canto na documentação é de 1785, ou seja, antes da hegemonia nagô, assim, "talvez fosse invenção jeje, nação que antecedeu aquela como a mais numerosa dentre as encontradas em Salvador." (p.83).

O ambiente de trabalho dos cantos era um espaço de convivência e formação de significados simbólicos. Cada canto possuía um capitão, que era a liderança reconhecida pelo grupo, sendo responsável pela organização e supervisão dos trabalhos. Além disso, os interesses desses trabalhadores muitas vezes entravam em conflito com as pretensões das autoridades. Nesse sentido, os conflitos entre africanos e autoridades em Salvador se intensificaram após a revolta dos malês em 1835. No mesmo ano da revolta, a assembleia legislativa provincial tentou substituir os cantos por capatazias com o posto de capataz para o líder que deveria substituir o capitão de canto. Em outro regulamento, instituía-se a fiscalização das capatazias por inspetores nomeados pelos juízes de paz de cada freguesia. Essas medidas iam de encontro com os costumes cultivados nos cantos, que prezavam pela autonomia. Vitória dos cantos, a lei e o regulamento não vingaram e no ano de 1837 foram revogados. Essas e outras questões são abordadas no quarto capítulo, Controle e conflito no mercado negro: antecedentes.

A repressão do governo provincial aos africanos é tema do quinto capítulo, A voz e a vez do governo provincial. A perseguição incluiu arrocho fiscal e excessiva vigilância. Buscava-se reprimir, constranger e expulsar os africanos de Salvador. Francisco Gonçalves Martins, presidente da província da Bahia na década de 1850, ganhou destaque pelo seu afinco na execução de políticas africanofóbicas. Nesse sentido, aprovou a lei dos saveiros, que proibiu 
a participação de africanos enquanto remadores de saveiros, tornando esse ofício exclusivo para livres ou libertos nacionais. Outras medidas de restrições aos africanos foram adotadas, tais como a proibição de africanos libertos, livres e escravizados, de negociar carne verde e fato, tanto nos açougues como pelas ruas da cidade.

Foi nesse cenário de perseguição e hostilidade que no dia primeiro de julho de 1857, em resposta à postura que obrigava matrícula e uso de uma chapa metálica para identificação dos ganhadores, que ocorreu a greve. Como foi dito, a matrícula custaria 2mil-réis e a chapa 3mil-réis. A principal fonte utilizada para reconstrução dos fatos foram os periódicos do período que fizeram a cobertura da paralisação. Em uma das matérias noticiadas naqueles dias chegou a ser utilizado o termo "revolução dos ganhadores" na caracterização do movimento grevista. A paralisação comprometeu a movimentação da cidade, o que gerou escassez de mercadorias, inclusive de alimentos, e consequente carestia. A associação Comercial da Bahia, dirigida pelos grandes e enriquecidos negociantes, prejudicados com a parada africana, pressionou o governo a tomar as medidas necessárias. Acreditava-se que o principal motivo da greve estava no pagamento das taxas, o que se mostrou uma leitura equivocada. A obrigatoriedade do uso da chapa de identificação incomodava os africanos o suficiente para continuarem parados mesmo depois de extinguidas as taxas de matrícula.

A chapa poderia lembrar os grilhões dos condenados ao trabalho forçado, assim "sendo o ganhador um liberto, lembrava-lhe sua passagem, em geral recente, pelo julgo escravocrata." (p.84). A chapa danificava a autoestima dos ganhadores e isso foi motivo suficiente para continuarem a greve. Reis indica que os africanos estavam com "Michel de Foucault: o corpo está diretamente mergulhado num campo político". (p.184). Assim, o autor utiliza Foucault na compreensão das tensões envolvidas na punição e controle dos corpos. Essa percepção também está de acordo com o conceito de economia moral do trabalho, inspirada em E. P. Thompson, mobilizado pelo autor, ao 
REIS, João José. Ganhadores: a greve negra de 1857 na Bahia. São Paulo: Cia das Letras, 2019,451p.

indicar que as reivindicações não estavam apenas no campo econômico e abrangiam também o cultural e simbólico.

A greve foi do dia 1 a 12 de julho de 1857 e a coesão e organização dos ganhadores surpreenderam as autoridades e a elite do período, uma vez que africanos libertos e escravizados uniram-se em suas causas. A ligação social entre os africanos, e a hegemonia nagô, assim como a dinâmica organização dos cantos, na argumentação de Reis, possibilitaram a articulação do movimento grevista. Nesse processo histórico estaria sendo gestado uma noção de pertencimento de classe, "os africanos tinham plena consciência de estarem sendo marcados para baixo, desclassificados com os “"operários de outras classes"”. Assim nasce o sentimento coletivo de classe". (p.211).

Os capítulos finais da obra são dedicados aos processos desenrolados após 1857. A perseguição aos africanos e o sentimento africanofóbico continuou na década de 1860, assim como a resistência e pequenas reivindicações individuais por partes dos africanos, que contestavam no cotidiano as desigualdades e restrições impostas. No capítulo 10, Rescaldo, podemos observar parte do ambiente social após a greve. No correr da segunda metade do século XIX, a presença africana diminuiu e na década de 1880 a maioria dos ganhadores já eram crioulos, ou seja, nascidos no Brasil. As regras mudaram, e buscava-se novos meios de vigilância para a crescente população de crioulos livres. Reis aponta que no decorrer da segunda metade do século XIX existiu a africanização dos crioulos na Bahia, pois o olhar de desconfiança passou dos africanos, que se tornaram quase inexistentes, para os descendentes. No capítulo 14, Dispersão e conflito nos cantos, podemos acompanhar indícios das intrigas e divergências entre ganhadores e as consequentes desfiliações de determinados cantos, alguns ganhadores mudavam de cantos ou apenas se desfiliavam em decorrência de divergências internas. Com a diminuição do número de africanos, a liga social nagô também se enfraqueceu nas décadas de 1870-80, apesar de não ter desaparecido totalmente. No fim do século XIX, o cenário já era bem diferente daquele que foi palco dos acontecimentos da greve do ano de 1857. 
Em síntese, ao longo da resenha é possível perceber a importância e relevância da obra, que abrange um acontecimento ainda pouco conhecido pela historiografia. Para os especialistas o livro contribui com a riqueza de detalhes, o cuidado metodológico com as fontes pesquisadas e o amplo diálogo bibliográfico. Para aqueles curiosos e com desejo de conhecer um pouco mais dessa história, o livro apresenta leitura fluída, instigante e bem documentada. 